\title{
Robo1 and 2 repellent receptors cooperate to guide facial neuron cell migration and axon projections in the embryonic mouse hindbrain
}

\author{
Hannah N. Gruner, Minkyung Kim, and Grant S. Mastick \\ Department of Biology, University of Nevada, 1664 N Virginia St, Reno, NV 89557, USA. \\ gmastick@unr.edu
}

\begin{abstract}
The facial nerve is necessary for our ability to eat, speak, and make facial expressions. Both the axons and cell bodies of the facial nerve undergo a complex embryonic developmental pattern involving migration of the cell bodies caudally and tangentially through rhombomeres, and simultaneously the axons projecting to exit the hindbrain to form the facial nerve. Our goal in this study was to test the functions of the chemorepulsive receptors Robo1 and Robo2 in facial neuron migration and axon projection by analyzing genetically marked motor neurons in double mutant mouse embryos through the migration time course, E10.0-E13.5. In Robo1/2 double mutants, axon projection and cell body migration errors were more severe than in single mutants. Most axons did not make it to their motor exit point, and instead projected into and longitudinally within the floor plate. Surprisingly, some facial neurons had multiple axons exiting and projecting into the floor plate. At the same time, a subset of mutant facial cell bodies failed to migrate caudally, and instead either streamed dorsally toward the exit point or shifted into the floor plate. We conclude that Robo1 and Robo2 have redundant functions to guide multiple aspects of the complex cell migration of the facial nucleus, as well as regulating axon trajectories and suppressing formation of ectopic axons.
\end{abstract}

\section{Graphical abstract: The Robo1 and 2 receptors are required for several steps in facial motor neuron cell body migration and axon projections.}

Schematic summarizing the findings. The wild type developmental time course of facial branchiomotor nucleus is shown on the left side of the hindbrain, and the altered development in Robo1/2 double mutants on the right. Slit expressing regions are shown by red (-) signs in the ventral midline (floor plate) and dorsal midline. The time course of cell migration is shown by a color gradient of green (E10.5) to blue to purple (E13.5). In wild type, the motor neurons first differentiate in $\mathrm{r} 4$, then they project primary axons to their dorsal exit point in $\mathrm{r} 4$ (green arrow), followed by a secondary migration of the neuron cell bodies caudally and then dorsally into r6 (curved arrow). In Robo1/2 double mutants, some primary axons project toward the dorsal exit point, but other axons project ventrally into then longitudinally within the floor plate, with many

Publisher's Disclaimer: This is a PDF file of an unedited manuscript that has been accepted for publication. As a service to our customers we are providing this early version of the manuscript. The manuscript will undergo copyediting, typesetting, and review of the resulting proof before it is published in its final citable form. Please note that during the production process errors may be discovered which could affect the content, and all legal disclaimers that apply to the journal pertain. 
of these midline projections forming as long secondary axons. Mutant neuron cell bodies migrate along three pathways, including some undertaking the normal caudal migration to r6, while other neuron cell bodies follow their axons either streaming dorsally toward the exit point or ventrally into the floor plate.

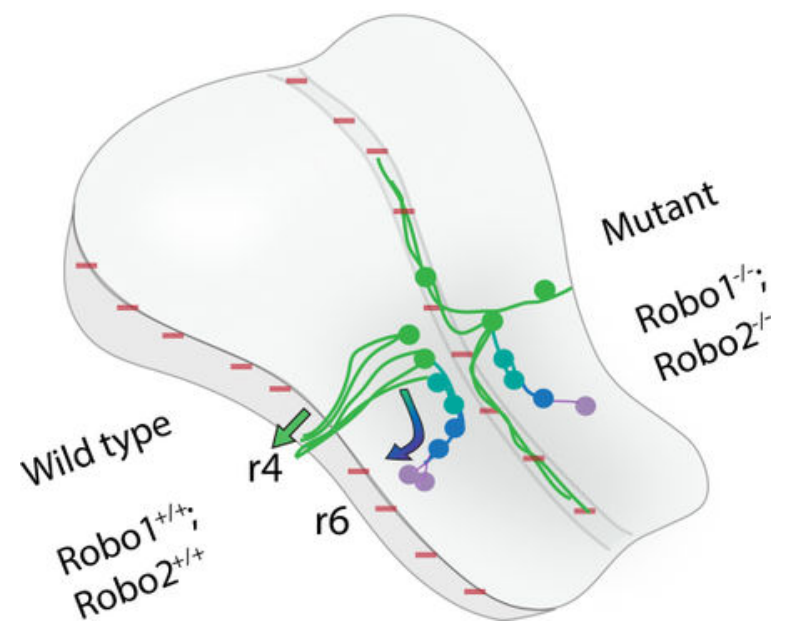

\section{Keywords}

axon guidance; chemorepulsion; neuron migration; hindbrain; Robo; Slit

\section{Introduction}

In the developing nervous system, neural progenitors must accurately navigate through the complex environment of the embryo to arrive at their final target. Neurons differentiate in specific locations and send out axon projections that are directed by a combination of guidance cues (Tessier-Lavigne et al., 1988). In the hindbrain, the rhombomere segments compartmentalize the differentiation of many of the cranial nerve populations, including the facial nerve (Lumsden and Keynes, 1989). From their birthplace in rhombomere 4 (r4), the facial branchiomotor nucleus (FBMN) undergoes a complex series of neuron cell body migrations while simultaneously sending out axons to exit to contribute the motor fibers of the facial nerve (Fritzsch and Nichols, 1993; Auclair et al., 1996; Fritzsch, 1998). However, key aspects of the guidance mechanisms for how the cell bodies migrate and axons extend in the CNS remain unclear.

The intricate migratory pattern of the facial nucleus and nerve suggests that integration of multiple guidance pathways is necessary to guide the assembly of this motor nucleus.

FBMN development is conserved in many aspects across a range of vertebrate embryos, and while our study focuses on the specific timing and patterns in mouse embryos, some developmental differences and several key regulatory factors have been discovered and studied in other vertebrates, particularly chick and zebrafish. Cell bodies of the branchiomotor (BM) aspect of the facial nucleus first differentiate in r4 via Hoxb1, Islet1, Phox2b, and hedgehog activity (Goddard et al., 1996; Studer et al., 1996; Varela-Echavarría et al., 1996; Chandrasekhar et al., 1998; Pattyn et al., 2000; Zhuang et al., 2013; Kim et al., 
2016). After appearing in ventral $\mathrm{r} 4$ on embryonic day 9.5 (E9.5), facial axons begin to arrive by E10.0 at their motor exit point in dorsal r4 (Niederländer and Lumsden, 1996). These initial projections by motor axons are thought to be guided by an unknown attractive cue secreted by the exit point, as well as repulsive cues restricting where axons can extend (Guthrie and Lumsden, 1992; Xiao et al., 2003; Bravo-Ambrosio and Kaprielian, 2011; Bravo-Ambrosio et al., 2012). During E10.5-E12.5, the chemorepulsive receptor Neuropilin-1 (Nrp1) and its ligands Sema-3A and VEGF164 are required for tangential migration and distal fasciculation of the facial cell bodies and axons, respectively (Kawakami et al., 1996; Kitsukawa et al., 1997; Varela-Echavarría et al., 1997; Schwarz et al., 2004).

While the facial axons exit to begin their navigation to targets in the periphery, their cell bodies are also undergoing complex migrations in the hindbrain. Beginning on E10.5, cell bodies shift from their ventral position in $\mathrm{r} 4$ to a more caudal location in $\mathrm{r} 6$. This translocation occurs via tangential migration, in which cell bodies translocate behind short leading axon-like protrusions that direct the cell body migration. Members of the Polar Cell Polarity (PCP) pathway (Prickle1, Prickle1b, Vangl2, Protein tyrosine kinase 7, Celsr11a-2-3, Frizzled3a, Frizzled7, Tbx20, Wnt5a, Scribble) are required to mediate this first step of caudal migration in mouse and in zebrafish (Carreira-Barbosa et al., 2003; Glasco et al., 2012; Mapp et al., 2010; Qu et al., 2010; Song et al., 2006; Vivancos et al., 2009; Yang et al., 2014). Mutating these genes prevents or limits facial cell bodies from successfully translocating to r6, implying these are necessary to promote caudal migration. Interestingly, the PCP proteins appear to act independently of Dvl1/2, suggesting a unique signaling cascade that utilizes different signaling molecules than most known Wnt pathways (Glasco et al., 2012). This indicates that other effectors, perhaps activated by Robo-Slit signaling, are utilized in the facial nucleus to activate Rho GTPase mediated cytoskeletal rearrangements. Also influencing the caudal migration is repellent activity from the floor plate, which is in part mediated by chemorepulsive Netrin1 activity (Murray, et al., 2010).

After arriving in $\mathrm{r} 6$, the facial neurons further migrate within r6, with ventral to dorsal (dorsolateral) migrations, and then ventricular to pial (radial). These shifts initiate in r6 on E12.5 and finish at E14.5, but are not as well defined mechanistically. Dorsolateral migration is regulated by the transcription factor Ebf1, as knockouts exhibit premature dorsolateral migration into r5 rather than r6 (Garel et al., 2000). The Dachsous-Fat PCP pathway is also necessary for dorsolateral migration, as Fat4/Dchs1 mutants fail to initiate this migration, and instead remain next to the floor plate (Zakaria et al., 2014). As the dorsal translocation is occurring, the cells also migrate radially from the ventricular surface to the pial surface. In Reeler mutant mice, the facial nuclei become disorganized and do not reach the pial surface, suggesting this migration depends on radial glial substrates (Goffinet, 1984; Rossel et al., 2005). Similarly, Cdk5, Dab1, and p35 are necessary for facial cell bodies to migrate to the pial surface (Ohshima et al., 2002). Although much is known about the migration of these neurons, our current knowledge paints an incomplete picture of which external signaling pathways are involved. In addition, the extent to which cell body migration and axonal extension are separable or coupled events is unclear. 
Slit-Robo repellents are highly conserved guidance molecules that guide many populations of cells during development (Kidd et al., 1998; Zallen et al., 1998; Brose et al., 1999). This signaling pathway guides a multitude of neuronal populations (Dickson and Gilestro, 2006; Mastick et al., 2010; Ypsilanti et al., 2010), and in a relatively few number of cases to guide cranial nerves (Li et al., 1999; Cho et al., 2007; Fouquet et al., 2007; Prince et al., 2009).

A previous study identified Slit-Robo functions to guide facial axons (Hammond et al., 2005). First, they established that the FBMN express Robo1/2 early (E12.0 rat, equivalent to E10.0 mouse), while their ligands Slit1 and 2 are expressed by the flanking ventral floor plate and dorsal rhombic lip (Hammond et al., 2005). This study then examined mouse embryos by retrograde labeling from the facial nerve at one early stage, E11.5, and found that single Robo mutants, particularly Robo2, had most axons projecting to exit normally while a few FBMN axons entered the floor plate. Slit-Robo signaling was shown to organize and guide facial axons toward the dorsal motor exit point at $\mathrm{r} 4$, while also repelling axons out of the Slit-producing floor plate, results which were supported in chick embryos using dominant negative constructs. Robo2 was found to be of particular importance for restricting facial axons to $\mathrm{r} 4$, preventing a subset of axons from coursing rostral or caudal relative to $\mathrm{r} 4$. Slit-Robo signaling likely acts in conjunction with other factors, such as Netrin1 signals which also function as floor plate-derived chemorepellents for migrating FBMN neurons (Murray et al., 2010). How Robo-Slit signaling influences the facial nerve and nucleus at earlier or later stages, and particularly the potential redundant functions of Robo1 and 2 in FMBN development, remained unresolved.

To extend the prior study, we set out to more closely examine the role of Robo-Slit signaling during the development of the facial nerve and nucleus by 1) examining multiple time points during development, 2) analyzing FBMN defects in Robo1/2 double mutant mice, and 3) using genetic markers for FBMN neurons in addition to retrograde tracing. We found that Slit-Robo signaling guides and organizes facial axons throughout several stages of neuron migration and axon projection. Additionally, we found enhanced defects in the positioning of FBMN cell bodies in Robo1/2 mutant embryos. Our data suggests a complex guidance mechanism by which a population of neuronal cell bodies and their axons simultaneously use Robo signaling in several steps of migration in the hindbrain.

\section{Results}

\section{Isl1-EGFP transgenic mice to visualize Robo-dependent FBMN axon and cell body migration}

Our overall goal was to compare the migration of the facial nucleus throughout development between control and Robo1/2 double mutant embryos. To map the development of the facial branchiomotor neurons, we used transgenic Isl ${ }^{\mathrm{MN}}$ :GFP-F embryos during various stages of development. This transgenic line expresses EGFP in motor neurons under the control of the Isl1 enhancer, crest1 (Lewcock et al., 2007), and proved to be effective to study the development of the FBMN. We first sought to confirm and extend the results of Hammond et al., which relied on retrograde tracing from the nerve exit point, at a single early stage, E11.5, with defects in axon projections seen Robo $^{+/+}$; Robo $2^{-/}$embryos (Hammond et al., 2005). Their retrograde tracing strategy would only label neurons which successfully 
projected axons to the exit point, whereas the Isl ${ }^{\mathrm{MN}}$;GFP transgenic marker would label all motor neurons and their axons, even those that failed to project an axon to the exit. The $\mathrm{Is}^{\mathrm{MN}}$;GFP transgenic marker was particularly useful for labeling axon projections, but less useful for cell bodies, particularly in crowded regions. In some cases to show the locations of the neuron cell bodies, we used Islet1/2 antibody labeling which labels the Islet1/2 transcription factors in the cell nucleus.

In control Isl ${ }^{\mathrm{MN}}$;GFP embryos, we observed the expected morphology of the FBMN at E11.5, consisting of many fascicles extending towards the dorsal motor exit point at $r 4$ (Figure 1A, F) and corresponding cell bodies transiting from $\mathrm{r} 4$ to $\mathrm{r} 6$ (Figure 1A). The neuronal cell bodies of the FBMN were located in streams, extending from r4 to r6 on either side of the floor plate, and as expected in control embryos, with no neuronal cell bodies located in the floor plate. As previously reported (Hammond et al., 2005), there were few if any longitudinal axons within the floor plate of control embryos (Figure 1B, E). In Robo1 $1^{+/+}$; Robo2 $2^{-/}$E11.5 littermate embryos carrying the Isl ${ }^{\mathrm{MN}}$;GFP, marker, the organization of the FBMN was somewhat altered, in agreement with Hammond, et al.. We saw a few longitudinal axons projecting from the FBMN migrating into the floor plate (Figure 1C, G). Axons of the FBMN extended into the floor plate both rostral (Figure 1D) and caudal (Figure 1G) relative to $\mathrm{r} 4$. Longitudinal axons in the floor plate emanating from the FBMN largely formed one large fascicle, however some axons appeared to defasciculate and then re-associate with the main bundle (Figure 1G). The majority of $\mathrm{RoboI}^{+/+} ; \mathrm{Robo}^{-/-}$ axons appeared to correctly exit at r4. Comparing the Robo2 mutants to controls, there was no statistically significant reduction in the number of fascicles emanating from the FBMN going towards the correct $\mathrm{r} 4$ exit point (Figure 1H, I). There was also a dramatic increase in the length of caudally projecting axons found in the floor plate (Figure $1 \mathrm{~J}$ ). Together these data demonstrate the effectiveness of using Isl ${ }^{\mathrm{MN}}$;GFP to study the development of the FBMN. Our observations also confirm the requirement of Robo2 to prevent the entry of some FBMN axons into the floor plate (Hammond et al., 2005).

Next we sought to examine if Robo1 and Robo2 play redundant roles in guiding the FBMN. Though Robo2 mutants appear to show some disorganization of FBMN axons, while Robo1 mutants have normal FBMN patterns (Hammond et al., 2005), it is possible that Robo2 may mask functions of Robo1 in guiding the FBMN. To start teasing apart the possible redundant functions of Robo1 and 2, Robo1 ${ }^{+/-} ;$Robo2 $^{-/-} \mathrm{E} 11.5 \mathrm{Isl}^{\mathrm{MN}}$;GFP embryos were compared to control littermates.

Again, control embryos showed the conventional morphology (Figure 2A, B, E, F). There were no longitudinal axons observed in the $\mathrm{r} 3$ floor plate (Figure 2B). The cell bodies migrated through $\mathrm{r} 5$ towards $\mathrm{r} 6$ (Figure 2E), and axonal projections in $\mathrm{r} 4$ successfully reached the motor exit point (Figure 2F). Similarly, Robo1 ${ }^{+/-}$; Robo $2^{-/}$embryos exhibited overall normal organization of the FBMN nucleus, suggesting that one allele of Robo1 is largely sufficient for guidance of the cell body migration (Figure 2C). More pronounced

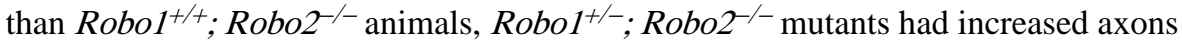
projecting into the floor plate (Figure 2D, G). Consistent with a subset of axons failing to project to the exit point, there were somewhat fewer FBMN fascicles projecting towards the r4 exit point in $\mathrm{Robol}^{+/-}$; $\mathrm{RoboO}^{-/-}$embryos (about one quarter less than $\mathrm{RoboI}^{+/+}$; 
Robo $2^{-/-}$controls) (Figure 2H, I). A one-way ANOVA (multiple comparison with a Bonferonni adjustment) suggested no statistical difference between Robo1+/+; Robo2 -/compared to Robo1+/-; Robo2 $-/-(\mathrm{p}=0.24)$, but did suggest a significant difference between Robo1+/+; Robo2 -/- and Robo1+/+; Robo2 +/+ (p=0.009). Despite the severe axon guidance errors observed, there was no difference in the tangential caudal migration of the cell bodies (Figure 2J). This suggests that Robo2 has a function in guiding axons to their exit point, while the partial loss of Robo1 did not result in more severe defects.

\section{Robo1 and Robo2 guide initial facial axon outgrowth towards the exit point}

To test if Robo1 and Robo2 act together to guide the FBMN, we examined the FBMN development of $\mathrm{Robo1}^{-/}$; Robo $2^{-/}$double mutant embryos, and also looked throughout the time course of FBMN development, both earlier and later, from E10.0-13.5. On E10.0 in control Isl ${ }^{\mathrm{MN}}$;GFP embryos, facial cell bodies differentiated adjacent to the floor plate in $\mathrm{r} 4$ (Figure 3A). These cells had already sent pioneer axons toward their ipsilateral dorsal motor exit point in $\mathrm{r} 4$ (Figure 3B). Some of the initial projections to the exit point had already formed thick bundles. On E10.0, facial cell bodies were stationary along the ventral aspect of r4, and had not yet begun migrating caudally.

In Robo1 $^{-/-}$; Robo2 $2^{-/-}$Isl $^{\mathrm{MN}}$;GFP E10.0 embryos, severe facial axon and cell body guidance defects were already evident. The majority of pioneer facial axons, rather than projecting dorsally toward the exit point, instead projected into the floor plate in mutant animals (Figure 3C). Bundles of axons coursed through the floor plate long distances both rostral and caudal to $\mathrm{r} 4$. Correspondingly, the number of axons reaching the dorsal motor

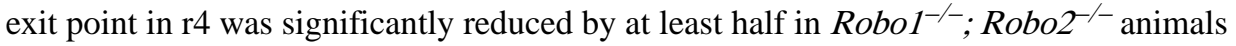
(Figure 3D, K). We also noted, but could not quantify in whole mount preparations, that facial neurons appeared to shift toward the ventral midline, consistent with previous observations suggesting that Robo signaling repels motor neuron cell bodies from the midline (Kim et al., 2014).

On E10.5 in controls, facial cell bodies started migrating tangentially from $\mathrm{r} 4$ to $\mathrm{r} 6$. This rostral to caudal migration was initiated by a few pioneer cell bodies that reached $\mathrm{r} 5$ at this stage (Figure 3E). Additional differentiated facial cell bodies appeared as the nucleus grew larger in $\mathrm{r} 4$. Axons that coursed to the exit point in $\mathrm{r} 4$ appeared more tightly fasciculated at this stage. On E10.5, the initial outgrowth of the IEE (inner ear efferent) commissural axons could be seen crossing the floor plate at $\mathrm{r} 4$ (Figure 3F).

On E10.5 in Robo1 $^{-/}$; Robo2 $2^{-/}$double mutant embryos, FBMN defects were much more severe than in single mutants. Some facial cell bodies initiated the expected tangential caudal migration in mutant animals (Figure 3G), though IslMN;GFP was expressed in all developing somatic motor neuron populations at this stage making the facial nucleus difficult to discern among the numerous motor neurons present in adjacent segments. For example, anterior segments, including likely trigeminal motor neurons, also had disorganized axonal projections, some of which likely merged into the $\mathrm{r} 4$ region (Figure 3G). FBMN axons did not appear to correct their guidance errors from E10.0. The fascicles in the floor plate were thicker, perhaps due to additional axons that use pioneer axons already in the floor plate as a scaffold to migrate onto (Figure $3 \mathrm{H}$ ). While some axons 
correctly exited the hindbrain into the periphery, these exiting bundles appeared similar to those on E10.0. Interestingly, short neurites that projected off the cell bodies in $\mathrm{r} 4$ were present on this stage, which were not observed in controls, suggesting growth cone stalling also occurs in the absence of Robo1/2 (data not shown).

\section{Robo1 $^{-/} ;$Robo2 $^{-/-}$facial cell bodies make several types of migration errors during tangential migration}

To observe the tangential migration in control and mutant animals we again used the $\mathrm{Isl}^{\mathrm{MN}}$;GFP transgene on E11.5, and due to later crowding of the transgenic marker, used lipophilic dye tracing to follow their migration trajectories in E12.5 embryos. Using the transgenic marker, controls showed thick axon bundles projecting to the exit point (Figure 4A). In controls, facial cell bodies started migrating caudally towards r6 on E11.5 (Figure 4A). Some leading cell bodies arrived in ventral $r 6$ by this stage, though in this early stage of rostral-caudal migration, many cell bodies were still translocating through $\mathrm{r} 5$. In the process of moving, cell bodies laid down trailing axon tracts indicative of their migratory route. This created a mixture of cell bodies and motor axon tracts in ventral r4r6 at this stage. In Robo $^{+/+}$; Robo ${ }^{+/+}$control animals, the separate IEE commissural axons had already traversed across the floor plate on this stage (Figure 4C). There were a few longitudinal axons visible in the embryonic floor plate, indicating a low level of errors attributed to the stochastic nature of axon guidance.

In Robo1 $^{-/-}$; Robo $2^{-/-}$mutants on E11.5, mutants thinner bundles of exiting axons were apparent (Figure 4D). Mutants also had bright round spots along the axon bundles, possibly ectopic cell bodies (Figure 4D). To visualize the motor neuron cell bodies more definitively, control and mutant embryos were labeled with an antibody against the Islet1/2 transcription factors, which labels the nuclei of motor neurons (Figure 4G, H). The mutants showed streams of motor neurons migrating dorsally, suggesting that in the absence of Robo1/2 function that some facial motor neurons follow their axons toward their exit point. To quantify the failure (or delay) in caudal migration, comparison of the ventral GFP+ area (which includes both cell bodies and axons) in $\mathrm{r} 4$ to $\mathrm{r} 5+6$ showed a significantly decreased ratio of GFP signal in the caudal region (Figure 4O). This is in contrast to Robo1 ${ }^{+/}$; Robo $2^{-/}$animals, which did not have cell body migration defects (Hammond et al., 2005), which we confirmed (data not shown). Despite there being fewer cell bodies in r5, those that started migrating along the rostral-caudal axis appeared to successfully do so and migrated to $\mathrm{r} 6$ with the same timing as in controls. Surprisingly, some bright GFP+ puncta could be seen in the floor plate (Figure 4F), suggesting that cell bodies also had migrated into the floor plate, presumably following their mis-guided axons.

On E12.5, the Isl1-GFP transgenic label was increasingly crowded, so we relied on retrograde labeling, primarily from the motor exit point in both control and Robo1/2 mutant embryos. By E12.5 in controls, the caudal migration of FBMN neurons was mostly completed (Figure 4I). The exiting axons merged into large fascicles at this stage, and most cell bodies were translocated to $\mathrm{r} 6$. Though tangential migration was nearly complete on E12.5, we noted some cell bodies were still in $\mathrm{r} 5$ (not shown). The presence of cell bodies en 
route to r6 was confirmed in both Isl-GFP embryos and dye tracing experiments (not shown).

In Robo1/2 mutant embryos, the FBMN remained highly disrupted (Figure 4K-N). To visualize the morphology and number of cell bodies that had successfully projected axons out to their exit point, retrograde tracing was performed by applying lipophilic dyes on the peripheral facial nerve on one side of the embryo (Figure 4K, L). The migratory path of the cell bodies toward $\mathrm{r} 6$ appeared disorganized as evidenced by the axon tracts that followed the cell bodies spanning r5-r6 (Figure 4I). Ectopic cell bodies located rostral to $\mathrm{r} 4$ or within the floor plate of $\mathrm{r} 4$ were seen in E12.5, similar to E11.5 (Figure 4K, L). Retrograde labels from the exit points labeled mostly neurons on the ipsilateral side, as expected, but FBMN cell bodies on the far side, contralateral to the dye label site, were also labeled (Figure 4K). Contralateral labels of neurons imply that one of two types of abnormal projections or migrations occurred: either contralateral-born neurons projected axons in error across the floor plate to the incorrect motor exit point, or ipsilateral-born neurons projected axons to the exit and later migrated their cell bodies contralaterally across the floor plate.

To confirm that longitudinal tracts in the floor plate had indeed came from the facial nucleus, floor plate dye labels more rostral (r1) and caudal (r8) to r4 were performed (Figure $4 \mathrm{M}, \mathrm{N}$ ). Back-labeled axons were traced back to cell bodies stalled in r4 (Figure 4M), although a few cell bodies in r6 were also labeled (data not shown). Interestingly, despite possessing long neurites that coursed longitudinally through the floor plate, some cell bodies back-labeled to $\mathrm{r} 4$ also possessed filaments that extended towards the $\mathrm{r} 4$ motor exit point (Figure 4N). However, it was difficult to directly visualize a motor neuron cell body producing multiple neurites because their cell bodies were generally crowded in ventral $\mathrm{r} 4$ (Figure 4M). Overall, the analysis of axon projections by retrograde labeling from the motor exit confirmed a severe reduction in successful axon exit, and considerable ectopic projections into the floor plate.

\section{Facial Branchiomotor cell bodies extend multiple neurites in Robo1/2 double mutants}

By E13.5 in control embryos, facial cell body migration and corresponding axon projections were completed through the hindbrain. To specifically back label and visualize the facial nucleus, and to avoid the over-crowding seen in Isl1-GFP labels, lipophilic dye was placed on the peripheral facial nerve (Figure 5). Labeled embryos were judged successful and chosen for further analysis if the peripheral nerve appeared intensely labeled, and if any direct labeling of the wall of the hindbrain was minimal. This labeling strategy showed that in control embryos, cell bodies had completed their migration along the tracts of facial axons laid down between r4-r6 (Figure 5A). Axon bundles had tightly fasciculated at this stage. Immediately after E12.5, the facial nuclei started migrating away from the ventral location in r6 to a new dorsal-lateral position. Concurrently, as we could ascertain by shifting the focal plane to the pial (outer) surface of the neural tube in r6, cell bodies also migrated radially away from the ventricular surface to the pial surface of r6 (Figure 5B). In control embryos, the only axons in the floor plate or contralateral side were those consistent with the IEE population that cross in anterior $\mathrm{r} 4$ (Figure 5E, F). 
In Robol $^{-/-}$; Robo $2^{--}$double mutant embryos, although the exiting nerve was much smaller, some axons could be back-labeled from the nerve exit point. The retrograde label successfully traced back to their cell bodies, but also labeled other long neurites that projected abnormally. A small subpopulation of the back-labeled FBMN migrated successfully to the correct location in r6 (Figure 5C). However, many mutant cell bodies were displaced. Tracks of axons spanning $\mathrm{r} 4$ to $\mathrm{r} 6$ were disorganized, much like what occurred on E12.5 (Figure 5C). Axon tracts that successfully arrived at the exit point appeared to merge into one or two bundles that exited the hindbrain. Radial migration appeared largely unaffected in those mutant neurons that did reach $\mathrm{r} 6$, as some cell bodies reached the pial surface of r6 (Figure 5D). Similarly, cell bodies correctly located at the pial surface were also in the correct dorsal-lateral position (Figure 5D). Stalling cell bodies were still present in $\mathrm{r} 4$ and $\mathrm{r} 5$ in mutant embryos (Figure 5C), and we noted that these cell bodies were not at the pial surface (not shown). Additionally, ectopic cell bodies migrated along the axon bundles reaching the $\mathrm{r} 4$ motor exit point.

Axon guidance defects within the hindbrain remain prevalent at this stage as well. Because these E13.5 labels were retrograde from the exit point, many of the long axons projecting into ectopic tracts apparently represent second (or multiple) axons from FBMN neuron cell bodies. Robo1 ${ }^{-/-}$; Robo $2^{-/-}$embryos had extensive neurons and processes growing into the floor plate, including longitudinal tracts, looping axons, and cell bodies (Figure 5G, H). Facial cell bodies on the contralateral side of the dye site extended axons to the wrong contralateral exit point (Figure 5G). A few cell bodies located in other rhombomeres, as far away as $\mathrm{r} 2$, also incorrectly sent axons to the $\mathrm{r} 4$ exit point and possessed multiple long neurites. Therefore, the E13.5 labels show an accumulation of errors of both cell bodies and axons, and reveal additional examples of FBMN neurons producing more than one long axonal projection.

\section{Discussion}

In our study, we found that Robo1/2 has a multifunctional role in regulating both the facial nucleus migration and the motor exit point pathfinding. We established that Robo1 and Robo2 receptors function redundantly to guide both FBMN axons and cell bodies. Examining Robo1 ${ }^{-/-}$; Robo $2^{-/}$embryos revealed much stronger and more diverse phenotypes than observed in Robo1 and Robo2 single mutant embryos or even Slit1 ${ }^{-1-}$;

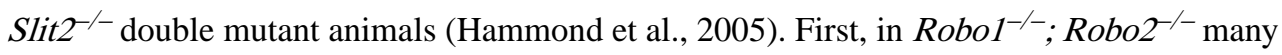
facial motor axons fail to make it to the $\mathrm{r} 4$ motor exit point and instead divert into the floor plate, which implies Slit proteins secreted from the floor plate (Holmes et al., 1998; Yuan et al., 1999) act to repel facial axons dorsally towards their exit point. Additionally, as facial axons collapse into the floor plate, they are likely attracted to floor plate secreted cues such as Wnt5a and Wnt7a (Vivancos et al., 2009). Second, the caudal migration of the nucleus is disrupted in Robo1/2 mutants, as cell bodies are observed stalling in $\mathrm{r} 4$ or migrating incorrectly into regions such as the floor plate, thus suggesting Robo-Slit signaling is required to guide facial cell bodies during tangential migration to r6. Third, we observed multiple long neurites projecting off facial cell bodies during their migration, suggesting Robo is important for suppressing the formation of ectopic or secondary neurites from FBMN neurons. 
Numerous motor neuron populations express Robo1 and Robo2 and are responsive to Slit2 (Holmes et al., 1998; Brose et al., 1999; Jaworski et al., 2010; Bravo-Ambrosio and Kaprielian, 2011), including the branchiomotor aspect of the facial nerve and nucleus (Hammond et al., 2005; Murray et al., 2010). All three Slits (Slit1, Slit2, Slit3) are highly expressed in the floor plate, spanning the length of the midbrain through the spinal cord (Brose et al., 1999; Holmes et al., 1998; Yuan et al., 1999). Slit2 is expressed in the ventral hindbrain during the entirety of migration of the facial nucleus, from E8.5 before facial cell bodies are even differentiated through E14.5 when the nucleus has settled to its final location (Geisen et al., 2008). Motor neurons also express Slit2 and 3, potentially regulating themselves in an autocrine fashion (Jaworski and Tessier-Lavigne, 2012). Consistent with potential autocrine guidance, the facial nucleus itself expresses Slits (Geisen et al., 2008; Kim et al., 2016), suggesting the facial nucleus may regulate its guidance or organization at later stages of development, a potential guidance mechanism that could be tested by celltype specific knockouts.

\section{Facial nerve projections towards the motor exit point are guided by Robo-Slit signals}

Our study validates that Robo signaling guides branchiomotor axons out of the floor plate. In our study, Robo1 ${ }^{-/}$; Robo2 $2^{-/}$double mutants exhibited more severe defects than single Robo1 or Robo2 or Slit ${ }^{-/}$; Slit $2^{-/}$double knockouts (Hammond et al., 2005). The extreme phenotypes with the axons and cell bodies alike suggests that Robo1 and Robo2 largely act redundantly to regulate this population. The previous group had found that some mutant axons migrated the floor plate and also crossed between the exit point fascicles in Robo mutants (Hammond et al., 2005). Extending those results, in our Robo1/2 double knockout animals we found most axons of the facial nucleus migrate into the floor plate. The in ovo electroporation of a dominant-negative Robo receptor experiments performed by

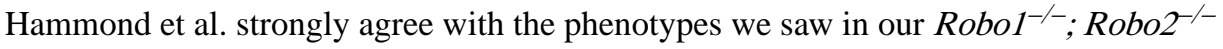
animals. They found axons that stalled, looped around, and failed to project away from the floor plate and to the exit point in their chicken experiments, which are all effects we saw in double mutant animals. The facial axons collapsing into the floor plate are largely seen migrating rostral or caudal relative to $\mathrm{r} 4$, suggesting there are attractive cues guiding them to these locations. In agreement with this, it was previously found Wnt5a and Wnt7a act as chemoattractants for facial axons (Vivancos et al., 2009). Indeed, Wnt5a and Wnt7a are expressed in the floor plate rostral and caudal to $\mathrm{r} 4$, respectively, and thus may be attracting facial axons that are no longer repelled by Robo-Slit signaling (Vivancos et al., 2009). In another study, the chemorepulsive effects of the Robo ligand Slit, and the Unc5a ligand Netrin, were previously both found to repel facial axons (Murray et al., 2010). Netrin was found to be particularly important in guiding facial neurons to their dorsal exit point, as facial axons in Netrin mutants turn towards the exit point too early or migrate into the floor plate (Murray et al., 2010). This is very similar, though less severe, than what we see in Robo1/2 double mutants suggesting there may be redundancies or interactions between Netrin and Robo signals. However, when Robo function is lost, the chemorepellent function of Netrin1 is evidently not sufficient to repel facial axons out of the floor plate.

Our results add to the lines of evidence that Slit-Robo signaling is important for motor axons to find their way to their exit points. For instance, Robo2, under the regulation of Nkx2.9, is 
necessary for spinal accessory motor neurons to correct exit the neural tube (BravoAmbrosio et al., 2012).The neural crest-derived motor exit point is joined later in development by boundary cap cells that keep cell bodies from leaving the periphery where at the same time are thought facilitate axon exit out of the neural tube by secreting an attractant (Niederländer and Lumsden, 1996). Deletion of speculation about other molecules expressed by boundary cap. Previous studies also showed that facial motor axons are not repelled by the motor exit point expressing Sema3A, but are instead repelled by Slit which appears to flank the exit point (Murray et al., 2010; Yuan et al., 1999). The expression pattern of Slit1/2 adjacent to the motor exit points suggests that Slits may be corralling axons to the correct exit point in the right rhombomere level. Together these data suggest Robo-Slit signaling is necessary for accurate guidance of the developing FBMN axons towards their dorsal $\mathrm{r} 4$ motor exit point.

\section{Caudal migration requires multiple signaling cascades, including Robo1/2-In}

our study, we found that Robo signaling is important for caudal migration of the facial nucleus. While it is well established that Slit-Robo signals can regulate dorsal-ventral projections of axons, it is not obvious how the ventral Slits could affect anterior-posterior (longitudinal) migration of cell bodies. One possibility is that Robo $1 / 2$ signaling integrates with other previously known guidance pathways to guide this complex migration of the cell bodies. This is in contrast to findings that Robo single mutants only have axon defects (Hammond et al., 2005). This difference is most likely attributable to using Robo1/2 double knockout mice. Our results are in agreement with experiments in which Hammond et al. found mis-positioned cell bodies when electroporating dominant-negative Robo constructs into chick embryos (Hammond et al., 2005). We found that in Robo1/2 mutant mice, some facial cell bodies remain in ventral $\mathrm{r} 4$ and do not undergo tangential migration. A few mutant cell bodies migrate into the periphery along their axons, whereas others move into the floor plate. These abnormal migrations could indicate that Robo1/2 signaling either acts to instigate, allow, or modulate caudal migration. Deletion of discussion of PCP Robo cross talk.

The migration defect in Robo1/2 mutants does not occur in all mutant facial cells nor are cell bodies mis-positioned in a consistent way, making it difficult to ascertain how Robo1/2 is regulating cell body position. One mechanism by which Robo-Slit signaling could affect tangential migration is by orienting leading processes away from, or parallel to, the floor plate, which is apparently highly attractive in the absence of Robos. It is also possible that the Slit-expressing dorsal neural tube also has a repulsive influence, thus restricting migration in a longitudinal direction.

Robo1/2 may also attenuate cell adhesion at the start of migration, thus acting as a permissive signal. In Robol $^{-/}$; Robo $2^{-/}$mutants, we observed facial cell bodies that appear to be stalled in $\mathrm{r} 4$ through the time period of E11.5 to E13.5, thus suggesting that adhesion between the neuroepithelium and the facial nuclei is not alleviated to release the cell bodies to migrate. Robo regulates cell migration by attenuating cadherin adhesion, thus breaking apart junctions between cells (Rhee et al., 2007). During migration of the FBMN, Robo may act to inhibit N-Cadherin mediated adhesion, as demonstrated in other systems (Rhee et al., 2007). Indeed, zebrafish N-Cadherin is necessary for preventing facial cell 
bodies from entering the floor plate, and is expressed in the surrounding neuroepithelium (Stockinger et al., 2011). The potential role of Robo1/2 signaling in mediating cell adhesion of the FBMN is an interesting possibility that warrants future study.

Lastly, the facial nucleus migration errors may be secondary or indirect effects of other substrates that were misplaced in Robo1/2 mutants, and future studies could use cell-specific knockouts to test whether the FBMN disruption may be due to changes in other Robodependent cells. In our study, we observed cell bodies misguided into the floor plate, which may be due to them following other misguided populations to the floor plate. In zebrafish, facial neurons undergoing tangential migration through $\mathrm{r} 5$ and $\mathrm{r} 6$ use the medial longitudinal fasciculus (MLF), an ipsilateral tract of axons connecting visual and auditory nuclei of the brain to the spinal cord, as a substrate to migrate on (Wanner and Prince, 2013). Without the MLF, non-pioneer facial cell bodies did not migrate successfully to r6. Though it has been suggested that the FBMN is located too dorsally in mouse to contact the MLF (Wanner et al., 2013), this has not been experimentally validated. Our previous work has shown without Robo-Slit signaling, the MLF collapses into the floor plate and forms long fascicules coursing through the floor plate (Farmer et al., 2008; Kim et al., 2014). This suggests that facial cell bodies adhere to the MLF as a substrate to mislead them into the floor plate. Alternatively, it is possible that facial axons make independent ventral errors, because of the lack of Slit-mediated floor plate repulsion, but turn longitudinally once they contact the ectopic MLF bundles within the midline.

\section{Dorsolateral and radial migration act independently of Robo signaling}

When facial cell bodies reach $\mathrm{r} 6$ on E12.5, they turn perpendicular towards the dorsal aspect of r6, a process complete by E14.5. Without Robo1/2 signaling, facial neuron cell bodies become misplaced during the period when caudal migration should be occurring, and fail to recover in later stages. Because many cell bodies fail to reach r6, it is not easy to determine if Robo is particularly important in regulating tangential migration. To ascertain whether Robo is needed in these later stages, an inducible or temporal specific knockout would be needed to see if the lack of tangential migration is due to earlier defects or a separate guidance mechanism.

In Robo1/2 double mutant mice, we observed that the mutant facial cell bodies that reach $\mathrm{r} 6$ do correctly migrate to the pial surface. Though Robo doesn't appear necessary for dorsolateral and radial migrations, the initial correct caudal location of the cell bodies may influence the ability of mutant facial cells to undergo dorsolateral migration.

\section{Robo1/2 signaling suppresses the formation of multiple long axons from facial motor neurons}

In Robo mutant animals spanning E10.0-E13.5, we observed that some facial cell bodies produced multiple long projections. Through our retrograde labeling experiments of the peripheral nerve, we observed facial axons, labeled because they made long primary axons that successfully projected to the motor exit point, were connected to axons at the same time making long projections caudally in the floor plate. Previously, these ectopic floor plate axons were observed in relatively lower numbers in Robo2 mutants (Hammond et al., 2005), 
and were attributed to both the FBMN and the IEE, which normally sends commissural axons across r4 (Fritzsch and Nichols, 1993). Though some of the longitudinal axons in the floor plate could be from the IEE in our mutant animals, our floor plate back labeling experiments on E12.5 showed that many longitudinal fascicles in the floor plate traced back to the location of the FBMN. Therefore, the retrograde labeling shows that Robo signaling has an unexpected function in suppressing the formation of two or more long axonal projections from motor neurons. In contrast, Slit/Robo signaling is known to promote sensory axon branching (Wang et al., 1999; Ozdinler and Erzurumlu, 2002; Yeo et al., 2004; Ma and Tessier-Lavigne, 2007), so our results reveal an unexpected Robo function. Moreover, it is surprising that motor neurons have the capacity to form multiple neurites, given their universal unipolar structure in vertebrates. The mechanism underlying Robo suppression of ectopic motor axons is unknown. It is interesting to note that both facial motor neurons (longitudinally migrating) and oculomotor axons (midline crossing) are led by an axon-like process that forms from the cell body as a secondary axon (Bjorke et al., 2016). We speculate that the ability of these subsets of motor neurons to form a secondary axon-like process must involve a repolarization of the cell body to generate a secondary growth center and projection, and perhaps this repolarization is subject to Robo regulation.

\section{Experimental Procedures}

\section{Mouse embryos}

Animal protocols were approved by the University of Nevada, Reno's Institutional Animal Care and Use Committee (IACUC) and in accord to the standards of the National Institutes of Health Guide for the Care and Use of Laboratory Animals. Embryonic mice were collected at embryonic day 10.0 (E10.0), E10.5, E11.5, E12.5, and E13.5. Noon of the day a plug was discovered was counted as E0.5. If between E10.0- E12.5 embryos were obtained through uterine dissection, put in fresh (made the same day) $4 \%$ paraformaldehyde (PFA) and fixed for a minimum of 24 hours. If embryos were E13.5 cardiac perfusion was performed. We bought CD-1 mice from Charles River Laboratory (Wilmington, MA). Limb buds were removed from freshly collected embryos to genotype Robo mutant embryos as previously described (Plump et al., 2002; Grieshammer et al., 2004). Robo1/2 founder mice were a generous gift of Marc TessierLavigne, of Rockefeller University, and were derived from separate Robo1 and Robo2 alleles which were obtained by screening for rare recombinants between the neighboring genes. Robo1+/-; Robo2+/- and Robo1-/-; Robo2-/- embryos were obtained from intercrosses of Robo1+/-; Robo2+/- animals. Robo1+/-; Robo2-/- heterozygotes were obtained from crosses between Robo1+/-; Robo2+/- and Robo1+/+; Robo2-/- animals. The Isl1 ${ }^{\text {MN }}$-EGFP strain was a gift of Samuel Pfaff (Lewcock et al., 2007), of the Salk Institute. To create stable heterozygous lines, Is11GFP mice were crossed with Robo1/2 mutant mice as well as CD1 mice.

\section{NeuroVue facial nerve tracing and antibody labeling}

The lipophilic fluorescent axon tracers NeuroVue ${ }^{\mathrm{TM}}$ Orange and NeuroVue ${ }^{\mathrm{TM}} \mathrm{Jade}$ were used to label the facial nucleus and trace facial axon trajectories in the peripheral branchial arches (Fritzsch et al., 2005). To trace the facial nerve a small piece of dye was cut into a triangle shape, and inserted superior to the otic vesicle on E10.0 and E10.5. Jade dye was 
placed above the left vesicle whereas orange was placed above the right vesicle. Similarly on E11.5, dye was anterior to the otocyst, and lastly on E12.5 and E13.5 dye was placed in the most rostral region within the developing ear. For peripheral nerve tracing experiments in control and mutant embryos, dye was placed in the same location to assure consistency. For floor plate fascicle tracing experiments, a smaller piece of dye than used in peripheral tracing experiments was placed directly in the floor plate several rhombomeres caudally or rostral relative to $\mathrm{r} 4$. After dye was placed embryos were incubated for 24 hours (E10.0, E12.5), or 48 hours (E13.5) at $37^{\circ} \mathrm{C}$ to allow the dye to diffuse to the distal nerve and nucleus. For labeling the neuron cell bodies, we used Islet1/2 antibody (DSHB 39.4D5; deposited by Jessell, T.M. / Brenner-Morton, S) (Ericson et al., 1992), which labels the nuclei of motor neurons.

\section{Imaging and preparations of tissue}

Embryos were assessed for successful fluorescent labels under a Leica upright fluorescence microscope. Neural tubes were dissected out while preserving the peripheral branchial arch. Hindbrains were prepared in an "open-book" conformation by cutting the dorsal most aspect of the neural tube along the dorsal midline. Neural tubes were incubated in $80 \%$ Glycerol in 4\% PFA for several hours before imaging. Once mounted, embryos were imaged using the Leica TCS-SP8 confocal microscope within 2 days of the end of dye diffusion to limit the amount of unwanted diffusion of the dye.

\section{Analysis and quantification}

Images were analyzed using the NIH's ImageJ software. Neural tube analysis: Number of exit point projections were analyzed by counting the number of dorsal projections coming immediately off the facial nucleus with all sizes of fascicles or axons were counted as equal. Length of fascicle in floor plate was measured by starting at the end of the IEE (r4/r5 boundary) and measuring the length of the fascicle caudally. Migrating cells were counted as the area of GPF+ facial cell bodies (which also includes GFP+ axons) in r5 and r6, while stationary cell bodies were counted as the area of the facial nucleus cell bodies (and axons) in r4. For figures 1 to 4 , a two-tailed Student's t-test was performed to determine significance; standard error of the mean was used to generate error bars.

\section{Acknowledgements}

The Robo1 ${ }^{-1} ;$ Robo2 $^{-/}$mice were generous gifts from Marc Tessier-Lavigne (Stanford; Genentech). The $\mathrm{Isl}^{\mathrm{MN}}$ :GFP-F mice were kindly provided by Samuel Pfaff (Salk Institute). We would like to especially thank Bernd Fritzsch (University of Iowa) for his expertise and advice with dye labeling for this project, for preliminary labels of cranial nerve exit points, and helpful comments on the manuscript. We thank Sarah Guthrie (University of Sussex) for helpful comments on the manuscript. We thank many members of the Mastick lab who provided feedback and help with the project, including Katherine Weller, Tatiana Fontelonga, Clare Lee, and Johnathan Pietz. This project was supported by NIH R01 EY025205 to G.S.M. Research reported in this publication used the imaging core facility supported by the National Institute of General Medical Sciences of the National Institutes of Health under grant number P20 GM103440, P20 GM103554, and P20 GM103650.

Funding was provided to G.S.M. by NIH R01 NS054740, R21 NS077169, and R01 EY025205. Core facilities at the University of Nevada Reno campus are supported by NIH COBREs GM103650 and GM103554, and Nevada INBRE GM103440. 


\section{References}

Auclair F, Valdés N, Marchand R (1996) Rhombomere-specific origin of branchial and visceral motoneurons of the facial nerve in the rat embryo. J Comp Neurol 369:451-461. [PubMed: 8743424]

Bjorke B, Shoja-Taheri F, Kim M, Robinson GE, Fontelonga T, Kim K-T, Song M-R, Mastick GS (2016) Contralateral migration of oculomotor neurons is regulated by Slit/Robo signaling. Neural Dev 11:18. [PubMed: 27770832]

Bravo-Ambrosio A, Kaprielian Z (2011) Crossing the border: molecular control of motor axon exit. Int J Mol Sci 12:8539-8561. [PubMed: 22272090]

Bravo-Ambrosio A, Mastick G, Kaprielian Z (2012) Motor axon exit from the mammalian spinal cord is controlled by the homeodomain protein Nkx2.9 via Robo-Slit signaling. Development 139:14351446. [PubMed: 22399681]

Bron R, Vermeren M, Kokot N, Andrews W, Little GE, Mitchell KJ, Cohen J (2007) Boundary cap cells constrain spinal motor neuron somal migration at motor exit points by a semaphorin-plexin mechanism. Neural Dev 2:21. [PubMed: 17971221]

Brose K, Bland KS, Wang KH, Arnott D, Henzel W, Goodman CS, Tessier-Lavigne M, Kidd T (1999) Slit Proteins Bind Robo Receptors and Have an Evolutionarily Conserved Role in Repulsive Axon Guidance. Cell 96:795-806. [PubMed: 10102268]

Carreira-Barbosa F, Concha ML, Takeuchi M, Ueno N, Wilson SW, Tada M (2003) Prickle 1 regulates cell movements during gastrulation and neuronal migration in zebrafish. Development 130:40374046. [PubMed: 12874125]

Chandrasekhar A, Warren JT, Takahashi K, Schauerte HE, van Eeden FJ., Haffter P, Kuwada JY (1998) Role of sonic hedgehog in branchiomotor neuron induction in zebrafish. Mech Dev 76:101115. [PubMed: 9767138]

Cho JH, Lépine M, Andrews W, Parnavelas J, Cloutier J-F (2007) Requirement for Slit-1 and Robo-2 in zonal segregation of olfactory sensory neuron axons in the main olfactory bulb. J Neurosci 27:9094-9104. [PubMed: 17715346]

Dickson BJ, Gilestro GF (2006) Regulation of commissural axon pathfinding by slit and its Robo receptors. Annu Rev Cell Dev Biol 22:651-675. [PubMed: 17029581]

Ericson J, Thor S, Edlund T, Jessell TM, Yamada T (1992) Early stages of motor neuron differentiation revealed by expression of homeobox gene Islet-1. Science (80- ).

Farmer WT, Altick AL, Nural HF, Dugan JP, Kidd T, Charron F, Mastick GS (2008) Pioneer longitudinal axons navigate using floor plate and Slit/Robo signals. Development 135:3643-3653 Available at: http://apps.webofknowledge.com/full_record.do? product=WOS\&search_mode=DaisyOneClickSearch\&qid=24\&SID=4BPmI6DfgoKobcM7Lbl\&p age $=1 \&$ doc $=5$ [Accessed November 8, 2012]. [PubMed: 18842816]

Fouquet C, Di Meglio T, Ma L, Kawasaki T, Long H, Hirata T, Tessier-Lavigne M, Chédotal A, Nguyen-Ba-Charvet KT (2007) Robo1 and robo2 control the development of the lateral olfactory tract. J Neurosci 27:3037-3045. [PubMed: 17360927]

Fritzsch B (1998) Of mice and genes: evolution of vertebrate brain development. Brain Behav Evol 52:207-217. [PubMed: 9787220]

Fritzsch B, Muirhead KA, Feng F, Gray BD, Ohlsson-Wilhelm BM (2005) Diffusion and imaging properties of three new lipophilic tracers, NeuroVue Maroon, NeuroVue Red and NeuroVue Green and their use for double and triple labeling of neuronal profile. Brain Res Bull 66:249-258. [PubMed: 16023922]

Fritzsch B, Nichols DH (1993) DiI reveals a prenatal arrival of efferents at the differentiating otocyst of mice. Hear Res 65:51-60. [PubMed: 8458759]

Gao C, Chen Y-G (2010) Dishevelled: The hub of Wnt signaling. Cell Signal 22:717-727. [PubMed: 20006983]

Garel S, Garcia-Dominguez M, Charnay P (2000) Control of the migratory pathway of facial branchiomotor neurones. Development 127:5297-5307. [PubMed: 11076752] 
Geisen MJ, Di Meglio T, Pasqualetti M, Ducret S, Brunet J-F, Chedotal A, Rijli FM (2008) Hox paralog group 2 genes control the migration of mouse pontine neurons through slit-robo signaling. Zoghbi HY, ed. PLoS Biol 6:e142. [PubMed: 18547144]

Glasco DM, Sittaramane V, Bryant W, Fritzsch B, Sawant A, Paudyal A, Stewart M, Andre P, Cadete Vilhais-Neto G, Yang Y, Song M-R, Murdoch JN, Chandrasekhar A (2012) The mouse Wnt/PCP protein Vangl2 is necessary for migration of facial branchiomotor neurons, and functions independently of Dishevelled. Dev Biol 369:211-222. [PubMed: 22771245]

Goddard JM, Rossel M, Manley NR, Capecchi MR (1996) Mice with targeted disruption of Hoxb-1 fail to form the motor nucleus of the VIIth nerve. Development 122:3217-3228. [PubMed: 8898234]

Goffinet AM (1984) Abnormal development of the facial nerve nucleus in reeler mutant mice. J Anat 138 ( Pt 2:207-215.

Grieshammer U, Plump AS, Wang F, Tessier-Lavigne M, Martin GR (2004) SLIT2 Mediated ROBO2 Signaling Restricts Kidney Induction to a Single Site. Dev Cell 6:709-717. [PubMed: 15130495]

Guthrie S, Lumsden A (1992) Motor neuron pathfinding following rhombomere reversals in the chick embryo hindbrain. Development 114:663-673. [PubMed: 1618133]

Hammond R, Vivancos V, Naeem A, Chilton J, Mambetisaeva E, Mambitisaeva E, Andrews W, Sundaresan V, Guthrie S (2005) Slit-mediated repulsion is a key regulator of motor axon pathfinding in the hindbrain. Development 132:4483-4495. [PubMed: 16162649]

Holmes GP, Negus K, Burridge L, Raman S, Algar E, Yamada T, Little MH (1998) Distinct but overlapping expression patterns of two vertebrate slit homologs implies functional roles in CNS development and organogenesis. Mech Dev 79:57-72. [PubMed: 10349621]

Jaworski A, Long H, Tessier-Lavigne M (2010) Collaborative and specialized functions of Robo1 and Robo2 in spinal commissural axon guidance. J Neurosci 30:9445-9453. [PubMed: 20631173]

Jaworski A, Tessier-Lavigne M (2012) Autocrine/juxtaparacrine regulation of axon fasciculation by Slit-Robo signaling. Nat Neurosci 15:367-369. [PubMed: 22306607]

Kawakami A, Kitsukawa T, Takagi S, Fujisawa H (1996) Developmentally regulated expression of a cell surface protein, neuropilin, in the mouse nervous system. J Neurobiol 29:1-17. [PubMed: 8748368]

Kidd T, Brose K, Mitchell KJ, Fetter RD, Tessier-lavigne M, Goodman CS, Tear G (1998) of the CNS Midline and Defines a Novel Subfamily of Evolutionarily Conserved Guidance Receptors. 92:205-215.

Kim K-T, Kim N, Kim H-K, Lee H, Gruner HN, Gergics P, Park C, Mastick GS, Park HC, Song M-R (2016) ISL1-based LIM complexes control Slit2 transcription in developing cranial motor neurons. Sci Rep 6:36491. [PubMed: 27819291]

Kim M, Farmer WT, Bjorke B, McMahon SA, Fabre PJ, Charron F, Mastick GS (2014) Pioneer midbrain longitudinal axons navigate using a balance of Netrin attraction and Slit repulsion. Neural Dev 9:17. [PubMed: 25056828]

Kitsukawa T, Shimizu M, Sanbo M, Hirata T, Taniguchi M, Bekku Y, Yagi T, Fujisawa H (1997) Neuropilin-Semaphorin III/D-Mediated Chemorepulsive Signals Play a Crucial Role in Peripheral Nerve Projection in Mice. Neuron 19:995-1005. [PubMed: 9390514]

Lewcock JW, Genoud N, Lettieri K, Pfaff SL (2007) The ubiquitin ligase Phr1 regulates axon outgrowth through modulation of microtubule dynamics. Neuron 56:604-620. [PubMed: 18031680]

Li H, Chen J, Wu W, Fagaly T, Zhou L, Yuan W, Dupuis S, Jiang Z, Nash W, Gick C, Ornitz DM, Wu JY, Rao Y (1999) Vertebrate Slit, a Secreted Ligand for the Transmembrane Protein Roundabout, Is a Repellent for Olfactory Bulb Axons. Cell 96:807-818. [PubMed: 10102269]

Lumsden A, Keynes R (1989) Segmental patterns of neuronal development in the chick hindbrain. Nature 337:424-428. [PubMed: 2644541]

Ma L, Tessier-Lavigne M (2007) Dual Branch-Promoting and Branch-Repelling Actions of Slit/Robo Signaling on Peripheral and Central Branches of Developing Sensory Axons. J Neurosci 27:68436851. [PubMed: 17581972] 
Mapp OM, Wanner SJ, Rohrschneider MR, Prince VE (2010) Prickle1b mediates interpretation of migratory cues during zebrafish facial branchiomotor neuron migration. Dev Dyn 239:1596-1608. [PubMed: 20503357]

Mastick GS, Farmer WT, Altick AL, Nural HF, Dugan JP, Kidd T, Charron F (2010) Longitudinal axons are guided by Slit/Robo signals from the floor plate. Cell Adh Migr 4:337-341. [PubMed: 20215865]

Mauti O, Domanitskaya E, Andermatt I, Sadhu R, Stoeckli ET (2007) Semaphorin6A acts as a gate keeper between the central and the peripheral nervous system. Neural Dev 2:28. [PubMed: 18088409]

Murray A, Naeem A, Barnes SH, Drescher U, Guthrie S (2010) Slit and Netrin-1 guide cranial motor axon pathfinding via Rho-kinase, myosin light chain kinase and myosin II. Neural Dev 5:16. [PubMed: 20569485]

Niederländer C, Lumsden A (1996) Late emigrating neural crest cells migrate specifically to the exit points of cranial branchiomotor nerves. Development 122:2367-2374. [PubMed: 8756282]

Ohshima T, Ogawa M, Takeuchi K, Takahashi S, Kulkarni AB, Mikoshiba K (2002) Cyclin-dependent kinase 5/p35 contributes synergistically with Reelin/Dab1 to the positioning of facial branchiomotor and inferior olive neurons in the developing mouse hindbrain. J Neurosci 22:40364044. [PubMed: 12019323]

Ozdinler PH, Erzurumlu RS (2002) Slit2, a branching-arborization factor for sensory axons in the Mammalian CNS. J Neurosci 22:4540-4549. [PubMed: 12040061]

Pattyn A, Hirsch M, Goridis C, Brunet JF (2000) Control of hindbrain motor neuron differentiation by the homeobox gene Phox2b. Development 127:1349-1358. [PubMed: 10704382]

Plump AS, Erskine L, Sabatier C, Brose K, Epstein CJ, Goodman CS, Mason CA, Tessier-Lavigne M (2002) Slit1 and Slit2 cooperate to prevent premature midline crossing of retinal axons in the mouse visual system. Neuron 33:219-232. [PubMed: 11804570]

Prince JEA, Cho JH, Dumontier E, Andrews W, Cutforth T, Tessier-Lavigne M, Parnavelas J, Cloutier J-F (2009) Robo-2 controls the segregation of a portion of basal vomeronasal sensory neuron axons to the posterior region of the accessory olfactory bulb. J Neurosci 29:14211-14222. [PubMed: 19906969]

Qu Y, Glasco DM, Zhou L, Sawant A, Ravni A, Fritzsch B, Damrau C, Murdoch JN, Evans S, Pfaff SL, Formstone C, Goffinet AM, Chandrasekhar A, Tissir F (2010) Atypical cadherins Celsr1-3 differentially regulate migration of facial branchiomotor neurons in mice. J Neurosci 30:93929401. [PubMed: 20631168]

Rhee J, Buchan T, Zukerberg L, Lilien J, Balsamo J (2007) Cables links Robo-bound Abl kinase to Ncadherin-bound beta-catenin to mediate Slit-induced modulation of adhesion and transcription. Nat Cell Biol 9:883-892. [PubMed: 17618275]

Rossel M, Loulier K, Feuillet C, Alonso S, Carroll P (2005) Reelin signaling is necessary for a specific step in the migration of hindbrain efferent neurons. Development 132:1175-1185. [PubMed: 15703280]

Schwarz Q, Gu C, Fujisawa H, Sabelko K, Gertsenstein M, Nagy A, Taniguchi M, Kolodkin AL, Ginty DD, Shima DT, Ruhrberg C (2004) Vascular endothelial growth factor controls neuronal migration and cooperates with Sema3A to pattern distinct compartments of the facial nerve. Genes Dev 18:2822-2834. [PubMed: 15545635]

Song M-R, Shirasaki R, Cai C-L, Ruiz EC, Evans SM, Lee S-K, Pfaff SL (2006) T-Box transcription factor Tbx20 regulates a genetic program for cranial motor neuron cell body migration. Development 133:4945-4955. [PubMed: 17119020]

Stockinger P, Maître J-L, Heisenberg C-P (2011) Defective neuroepithelial cell cohesion affects tangential branchiomotor neuron migration in the zebrafish neural tube. Development 138:46734683. [PubMed: 21965614]

Studer M, Lumsden A, Ariza-McNaughton L, Bradley A, Krumlauf R (1996) Altered segmental identity and abnormal migration of motor neurons in mice lacking Hoxb-1. Nature 384:630-634. [PubMed: 8967950] 
Tessier-Lavigne M, Placzek M, Lumsden AG, Dodd J, Jessell TM (1988) Chemotropic guidance of developing axons in the mammalian central nervous system. Nature 336:775-778. [PubMed: 3205306]

Varela-Echavarría A, Pfaff SL, Guthrie S (1996) Differential expression of LIM homeobox genes among motor neuron subpopulations in the developing chick brain stem. Mol Cell Neurosci 8:242-257. [PubMed: 9000439]

Varela-Echavarría A, Tucker A, Püschel AW, Guthrie S (1997) Motor Axon Subpopulations Respond Differentially to the Chemorepellents Netrin-1 and Semaphorin D. Neuron 18:193-207. [PubMed: 9052791]

Vivancos V, Chen P, Spassky N, Qian D, Dabdoub A, Kelley M, Studer M, Guthrie S (2009) Wnt activity guides facial branchiomotor neuron migration, and involves the PCP pathway and JNK and ROCK kinases. Neural Dev 4:7. [PubMed: 19210786]

Wang KH, Brose K, Arnott D, Kidd T, Goodman CS, Henzel W, Tessier-Lavigne M (1999) Biochemical purification of a mammalian slit protein as a positive regulator of sensory axon elongation and branching. Cell 96:771-784. [PubMed: 10102266]

Wanner SJ, Prince VE (2013) Axon tracts guide zebrafish facial branchiomotor neuron migration through the hindbrain. Development 140:906-915. [PubMed: 23325758]

Wanner SJ, Saeger I, Guthrie S, Prince VE (2013) Facial motor neuron migration advances. Curr Opin Neurobiol 23:943-950. [PubMed: 24090878]

Xiao T, Shoji W, Zhou W, Su F, Kuwada JY (2003) Transmembrane sema4E guides branchiomotor axons to their targets in zebrafish. J Neurosci 23:4190-4198. [PubMed: 12764107]

Yang T, Bassuk AG, Stricker S, Fritzsch B (2014) Prickle1 is necessary for the caudal migration of murine facial branchiomotor neurons. Cell Tissue Res 357:549-561. [PubMed: 24927917]

Yeo S-Y, Miyashita T, Fricke C, Little MH, Yamada T, Kuwada JY, Huh T-L, Chien C-B, Okamoto H (2004) Involvement of Islet-2 in the Slit signaling for axonal branching and defasciculation of the sensory neurons in embryonic zebrafish. Mech Dev 121:315-324. [PubMed: 15110042]

Ypsilanti AR, Zagar Y, Chédotal A (2010) Moving away from the midline: new developments for Slit and Robo. Development 137:1939-1952. [PubMed: 20501589]

Yuan W, Zhou L, Chen JH, Wu JY, Rao Y, Ornitz DM (1999) The mouse SLIT family: secreted ligands for ROBO expressed in patterns that suggest a role in morphogenesis and axon guidance. Dev Biol 212:290-306. [PubMed: 10433822]

Zakaria S, Mao Y, Kuta A, Ferreira de Sousa C, Gaufo GO, McNeill H, Hindges R, Guthrie S, Irvine KD, Francis-West PH (2014) Regulation of neuronal migration by Dchs1-Fat4 planar cell polarity. Curr Biol 24:1620-1627. [PubMed: 24998526]

Zallen JA, Yi BA, Bargmann CI (1998) The conserved immunoglobulin superfamily member SAX-3/ Robo directs multiple aspects of axon guidance in C. elegans. Cell 92:217-227. [PubMed: 9458046]

Zhuang S, Zhang Q, Zhuang T, Evans SM, Liang X, Sun Y (2013) Expression of Isl1 during mouse development. Gene Expr Patterns 13:407-412. [PubMed: 23906961] 


\section{Bullet points:}

- $\quad$ Robo1 and 2 functions were tested in facial neuron cell body migration and axon projections.

- In Robo1/2 double mutant mouse embryos, facial cell bodies and axons abnormally shifted into the hindbrain floor plate.

- Some motor neurons projected two or more long axons.

- Cell body tangential migration into the caudal hindbrain was disrupted.

- Robo receptor-mediated repulsion is required for facial axon projection and cell body migration. 

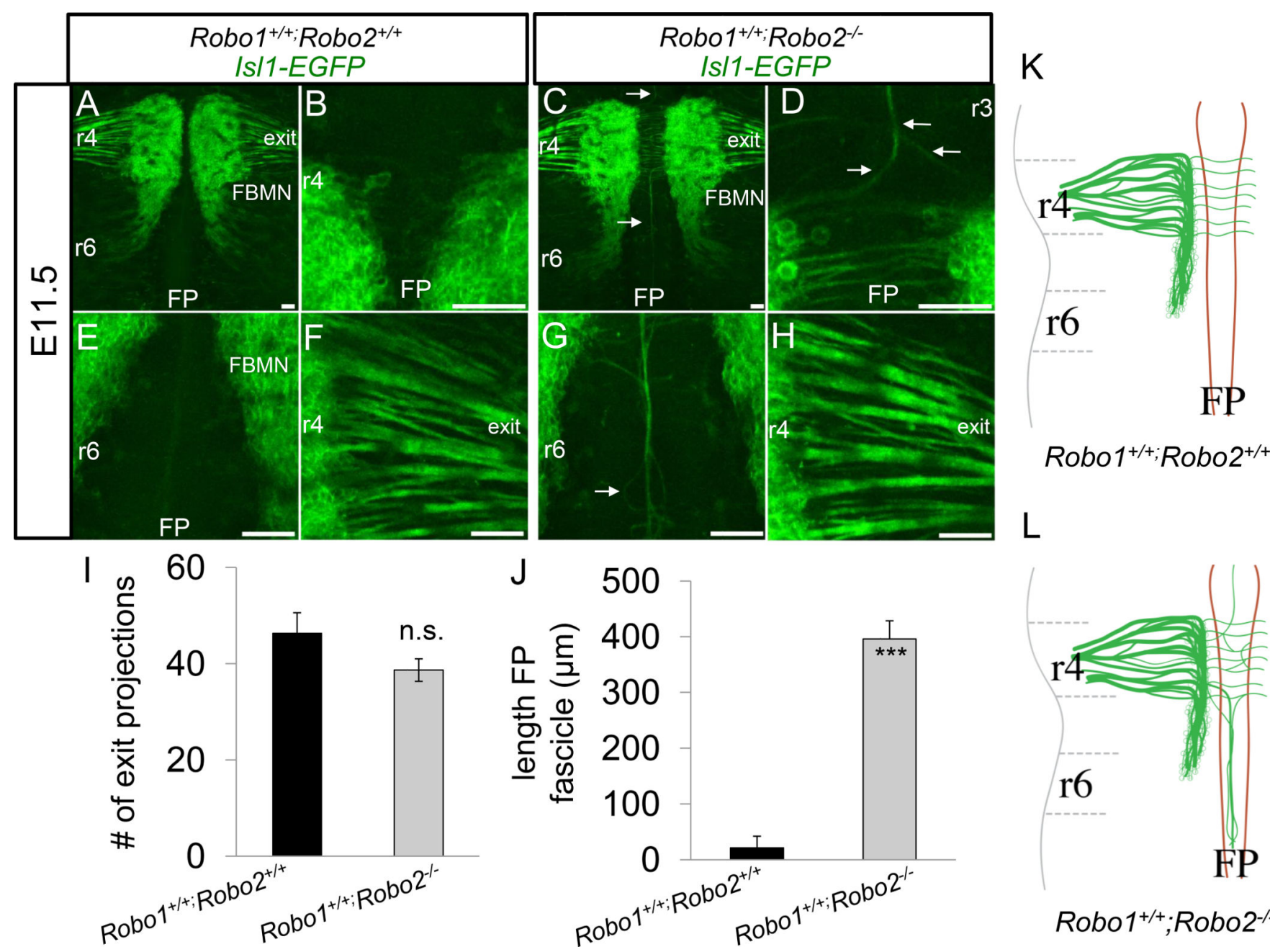

Figure 1. A subset of facial axons enter the hindbrain floor plate in Robo2 single mutants.

Transgenic mice, Isl ${ }^{\mathrm{MN}}$ :GFP, expressing EGFP under the control of somatic motor neuron specific enhancer, Is11, were utilized to visualize the facial nucleus and nerve. E11.5 openbook Isl1-EGFP hindbrains comparing control (A, B, E, F) and $\operatorname{Robol}^{+/+} ; \operatorname{Robo}^{-/-}$(C, D, G, H) embryos. A. In control embryos, axons from the FBMN successfully extended towards the dorsal motor exit point (denoted as exit) in r4; a higher magnification view is shown in panel F. B, C. Control embryos had no apparent longitudinal axons within the r3 (B) or r6 (C) floor plate. C. Similar to control, the majority of Robol $^{+/+}$;Robo2 ${ }^{-1-}$ FBMN axons extended successfully to their $\mathrm{r} 4$ exit point embryos. D, G. FBMN axons projected longitudinally into the floor plate (arrows), migrating to r3 (D) and r6 (G). I. Quantification of the number of fascicles branching directly off the FBMN nucleus. J. Average length of fascicles projecting into the caudal FP in control and $\mathrm{Robol}^{+/+} ; \mathrm{Robo}^{-/-}$embryos. K, L. Schematics of E11.5 FBMN nucleus migration and axon projection patterns. K. In control animals, axons projected to the exit point in rhombomere 4. L. In Robo2 mutants, some axons collapsed into the floor plate. Scale $50 \mu \mathrm{m} . \mathrm{n}=3, \mathrm{E} 11.5 \operatorname{Robo1}^{+/+} ; \operatorname{Robo}^{+/+}$. $\mathrm{n}=3$, E11.5 Robo1 ${ }^{+/+} ;$Robo2 $^{-/}$. 


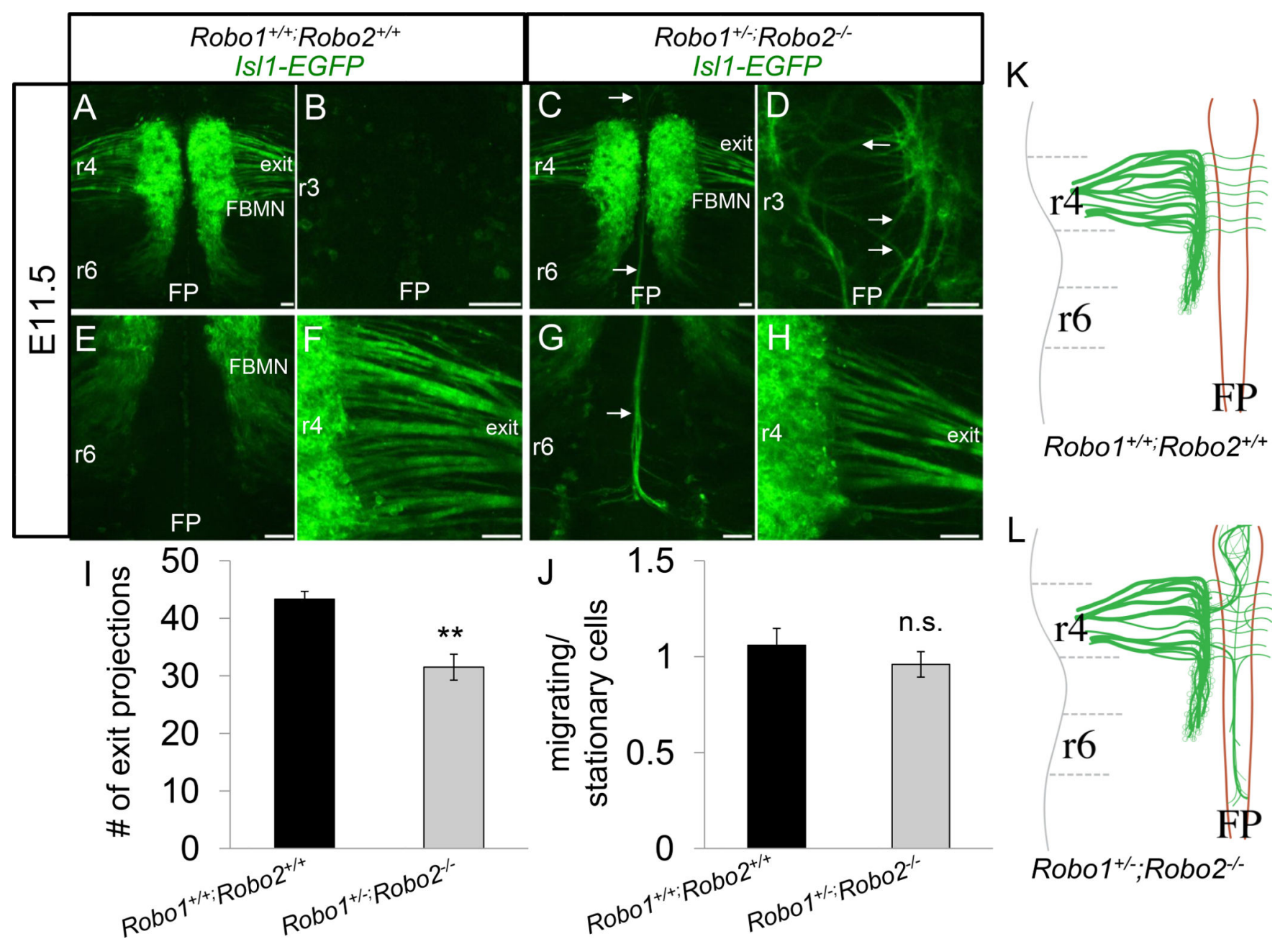

Figure 2. Robo1 is redundant with Robo2 in FBMN axon guidance.

E11.5 open-book Is11-GFP hindbrains comparing control (A, B, E, F) and

Robo1 $^{+/-} ; \operatorname{Robo}^{-1-}(\mathbf{C}, \mathbf{D}, \mathbf{G}, \mathbf{H})$ embryos. A, B, E, F. Control FBMN nuclei undertook caudal migration towards r6 and projected axons to $\mathrm{r} 4$ exit point. $\mathbf{C}, \mathbf{D}, \mathbf{G}, \mathbf{H}$.

Robo1 $1^{+/} ;$Robo $^{-/-}$embryos had many axons projecting toward the exit, but also dramatic entry of some FBMN axons into the floor plate. D. Axons projecting anteriorly from r4 were observed looping around in the floor plate of r3. G. Axon bundles projected caudally into the r6 floor plate in large bundles. H. Many axons projected towards the r4 exit point. I. Measurement of the number of fascicles (including both thick and thin fascicles) projecting towards the r4 exit point in control and $\mathrm{RoboI}^{+/-} ; \mathrm{Robo}^{-/-}$embryos. J. Quantification of the ratio of the GFP+ area covered by migrating (r5-r6) cell bodies (and axons) divided by the r4 area containing stationary cell bodies (and axons). K, L. Schematic of control E11.5 morphology compared to $\mathrm{RoboI}^{+/-} ; \mathrm{Robo}^{-/-}$mutants, which had increased numbers of axons migrating into the FP. Scale $50 \mu \mathrm{m} . \mathrm{n}=3, \mathrm{E} 11.5 \operatorname{Robo}^{+/+} ; \operatorname{Robo}^{+/ t} . \mathrm{n}=4(\mathrm{I}), \mathrm{n}=3(\mathrm{~J})$, E11.5 Robol $^{+/} ;$Robo2 $^{-/}$. 

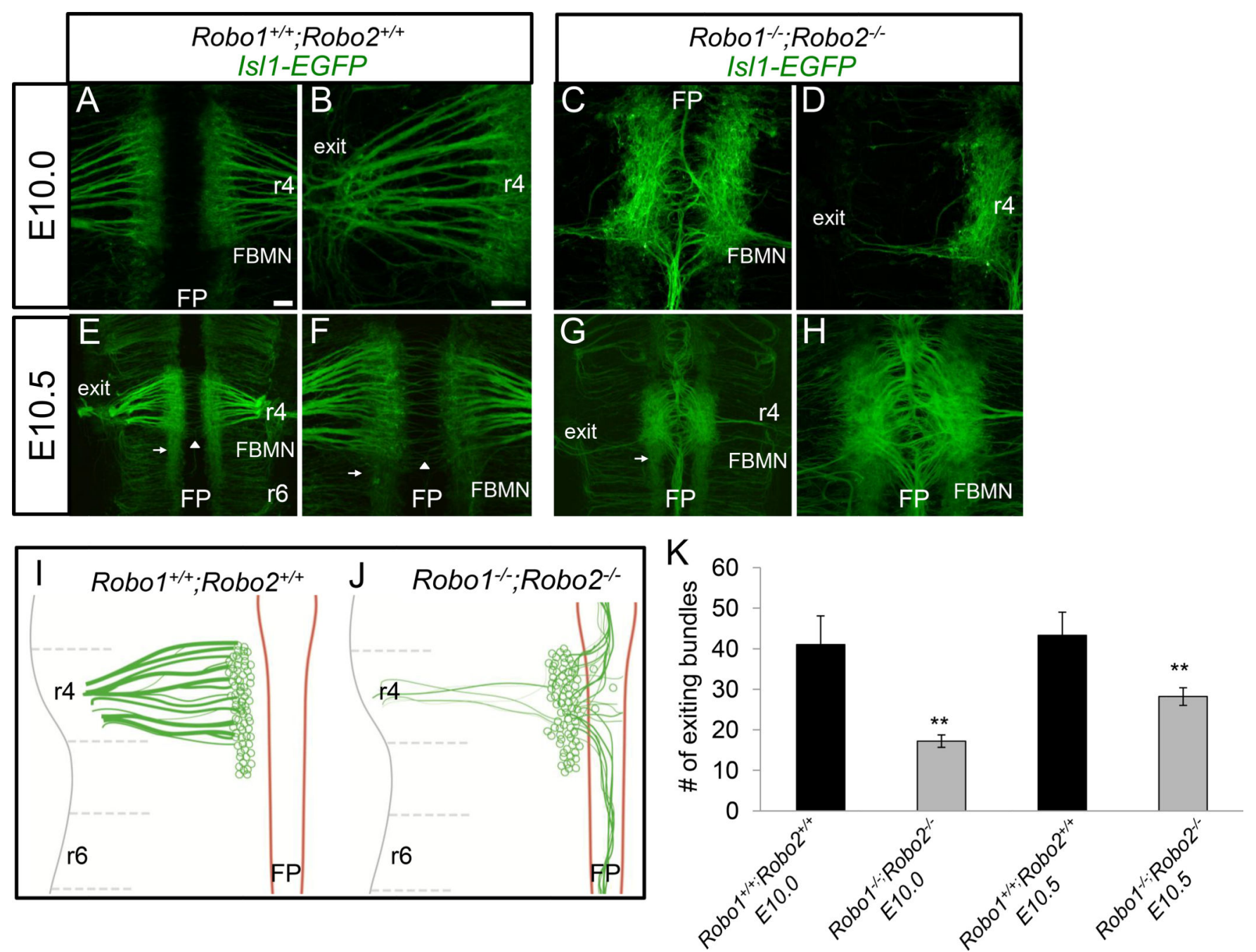

Figure 3. Robo1 and Robo2 are required to guide pioneer facial axons toward their $\mathbf{r} 4$ dorsal exit point.

E10.0-E10.5 open-book Isl1-EGFP hindbrains comparing control (A, B, E, F) and Robo1 $^{-/-} ;$Robo $^{-/-}(\mathbf{C}, \mathbf{D}, \mathbf{G}, \mathbf{H})$ embryos. A-D. E10.0 mouse hindbrains arranged rostral, top; floor plate (FP), center. A, B. In control embryos, facial axons coursed from the facial branchiomotor nucleus (FBMN) towards the dorsal motor exit point (denoted as exit) in r4; a higher magnification view is shown in panel B. C. In Robo1 $^{-1-} ;$ Robo $^{-1-}$ embryos, motor axons were misguided into the floor plate. Likewise, the nucleus was shifted closer to the floor plate. D. A higher magnification view in $\mathrm{Robo1}^{-/-} ; \mathrm{Robo}^{-/-}$mice to show that few axons projected dorsally from the FBMN to their exit point. E-H. By E10.5, facial axons did not self-correct after initial projection errors. E,F. On E10.5 in control, FBMN cell bodies migrated caudally (arrow). The commissural axons of the inner ear efferents (IEE) nerve (arrowhead) also crossed the midline. G. On E10.5, most facial axons did not project towards the exit point and instead projected in bundles rostrally and caudally in the floor plate. A reduced stream of neurons migrated caudally (arrow). H. High magnification of ventral midline. I, J. Schematics of E10.010.5 FBMN nerve projections, showing decreased axon projections toward the exit point, and a shift of projections into and longitudinally 
within the floor plate. The tangential caudal migration of cell bodies started on E10.5, and was characterized by a subpopulation of FBMN pioneering this route. $\mathbf{K}$. Graph quantifying the number of facial axon bundles projecting to the $\mathrm{r} 4$ exit point in E10.0 and E10.5 control (black) compared to $\mathrm{Robo1}^{-/} ; \mathrm{Robo2}^{-/-}$mutants (gray). Scale $50 \mu \mathrm{m}$. Error bars show

S.E.M.; significance was measured using students t-test, ${ }^{*} \mathrm{p}<0.01$. $\mathrm{n}=4, \mathrm{E} 10.0$

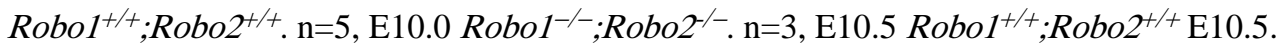
$\mathrm{n}=5$, Robo $^{-/-} ;$Robo $^{-/-}$. 

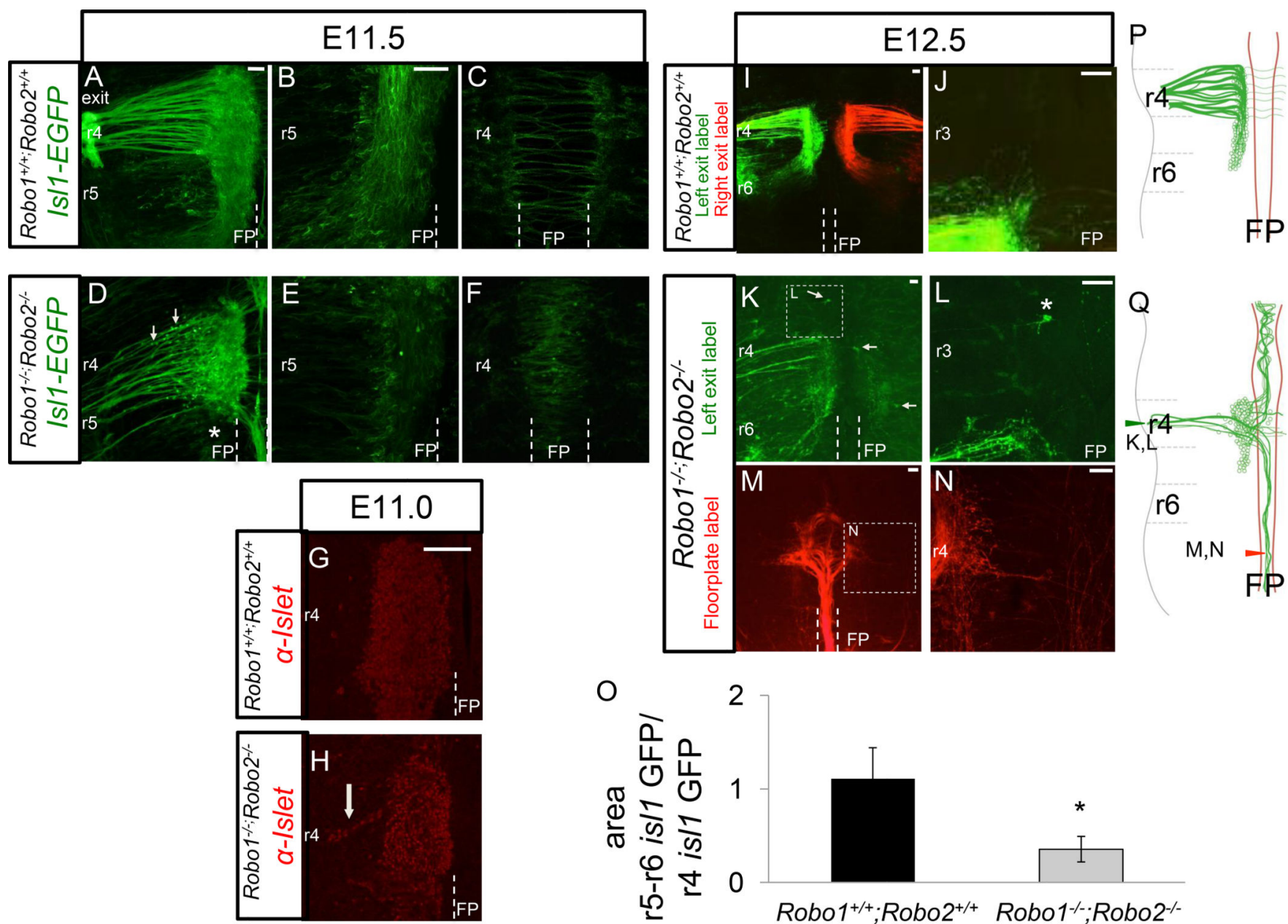

Figure 4. Robo1 and Robo2 regulate facial branchiomotor cell body position.

Control (A-C, G, H, K, L) and Robo $1^{-/} ;$Robo $^{-/-}$(D-F, I, J, M-P) E11.5 and E12.5 openbook hindbrains expressing Isl ${ }^{\mathrm{MN}}$ :GFP or labeled with NeuroVue tracers (M-P). A. On E11.5, facial axons added to fascicles already projecting to the motor exit point in control embryos. B. FBMN cell bodies migrate tangentially from ventral $r 4$ towards $r 6$. The majority of cell bodies were in $\mathrm{r} 5$, however some cell bodies had already made it to $\mathrm{r} 6$ by E11.5. C. Commissural axons of the IEE were the only axons seen crossing the floor plate in control embryos. D. In mutant E11.5 animals, FBMN cell bodies were ectopically positioned more dorsally in $\mathrm{r} 4$ (arrows), apparently migrating dorsally toward the exit point. In Robo1 ${ }^{-/} ;$Robo $^{-/-}$embryos, axons added to the existing pioneer axons projecting to the exit point or floor plate. The fascicles coursing through the floor plate had increased in size relative to E10.5 embryos, suggesting that some newly projecting axons did not find the $\mathrm{r} 4$ exit point and instead followed axons into the floor plate. Few cell bodies could be seen in the caudal migration stream $(*)$. E. There were significantly less cell bodies migrating caudally in mutant embryos, with the majority still residing in $\mathrm{r} 4$ (quantified in $\mathrm{O}$ ). F. On E11.5, cell bodies were ectopically located in the floor plate. G-H. Islet1/2 antibody labels (red) of E11.0 open book whole mounts to show motor neuron cell body positions. High magnification views showing in controls that neuron cell bodies remained confined to the 
ventral position of the nucleus in $\mathrm{r} 4(\mathbf{G})$, while streams of neuron cell bodies migrating dorsally from the $\mathrm{r} 4$ nucleus $(\mathbf{H}$, arrow), supporting the observation of dorsally migrating cell bodies seen by Is11-GFP in D. I, J. Retrograde tracing in E12.5 control using the lipophilic NeuroVue tracers from the exit point, showing symmetrical labeling in green from the left exit, and red from the right exit. J. High magnification view of $r 3$, showing the lack of any labeled neurons anterior to $\mathbf{r}$. K, L. Retrograde labels in E12.5 Robo1/2 mutant from the left exit point, with many fewer axons and cell bodies labeled. Neurons in ectopic positions can be seen in the floor plate and on the contralateral side (arrows), and also anterior to $\mathrm{r} 3(*$, high mag in $\mathrm{L})$. M, N. Retrograde tracing from a label site within the floor plate in $\mathrm{r} 8$, labeling a robust bundle of axons projecting longitudinally within the floor plate, and originating from cell bodies in $\mathrm{r} 4$. N. A few fibers (arrow) project dorsally toward the exit point, consistent with neurons with bifurcating axons that project both into the floor plate and toward the exit point. O. Quantification of the migration of Is11-GFP neurons, as in the examples shown in A and D. The graph shows the ratio of Isl1-GFP labeled areas in r5-6 (migrating cells plus axons) compared to the Isl1-GFP area in $\mathrm{r} 4$ (stationary cells plus axons). Significantly less migration occurs in Robo1/2 mutants. Error bars show S.E.M. ${ }^{*} \mathrm{p}<0.05 \mathrm{n}=5$ control, $\mathrm{n}=3$ Robo1 $^{-/-;}$Robo $^{-/}$. Scale bar $50 \mu \mathrm{m}$. 


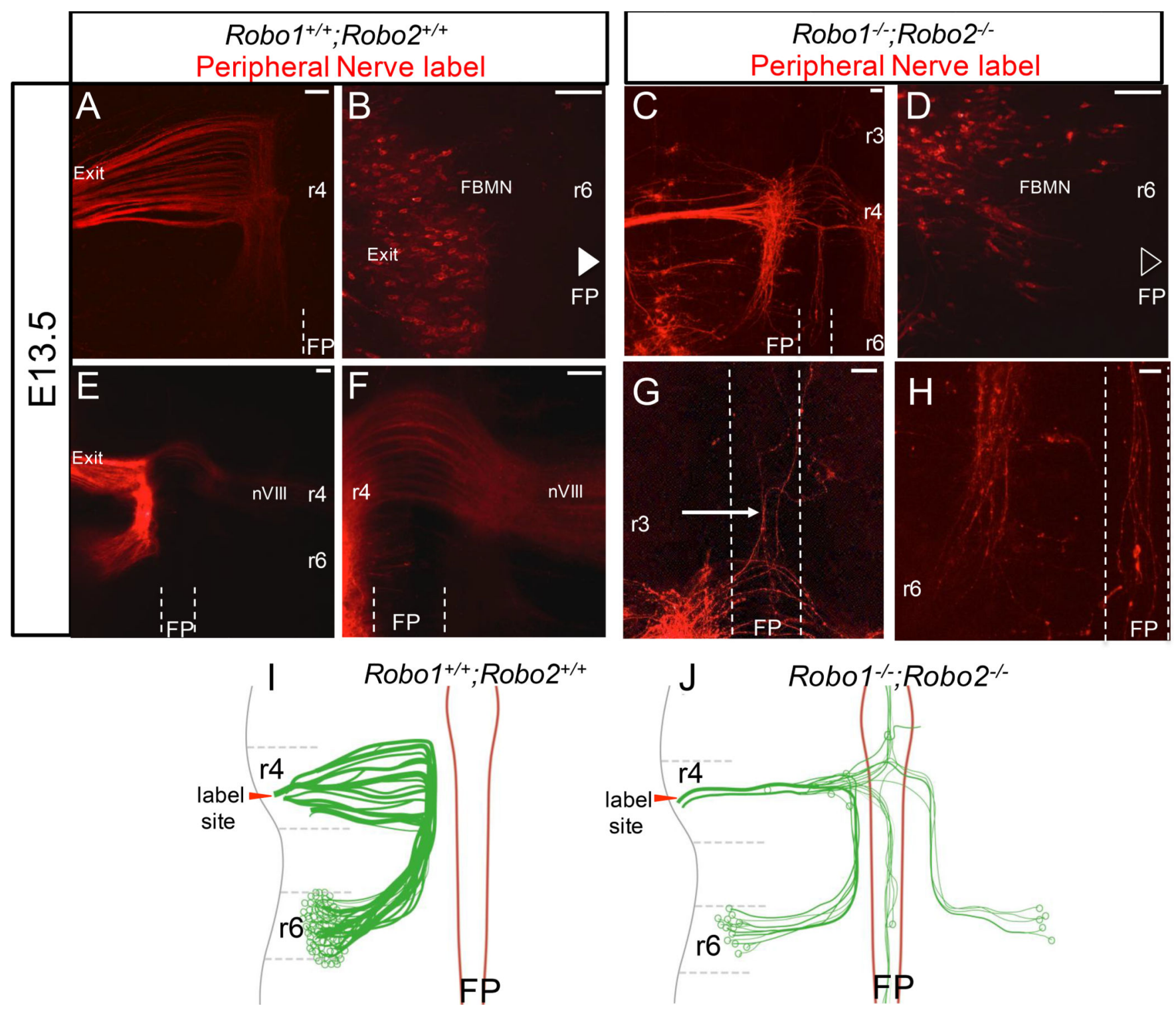

Figure 5. Subpopulations of facial cell bodies extend multiple long neurites in the absence of Robo1/2.

E13.5 open-book $\operatorname{Robo}^{+/+} ; \operatorname{Robo}^{+/+}(\mathbf{A}, \mathbf{B}, \mathbf{E}, \mathbf{F})$ and $\operatorname{Robo}^{-/-} ; \operatorname{Robo}^{--}(\mathbf{C}, \mathbf{D}, \mathbf{G}, \mathbf{H})$ facial nuclei retrogradely labeled with NeuroVue Orange dye; the rhombomere location of each picture is noted. In $\mathbf{B}$ and $\mathbf{D}$, embryos imaged pial side up to visualize cell body positions in the thicker hindbrain tissue. A-D. Dorso-lateral and radial migration patterns in both control and mutant embryos. A, B. $\operatorname{Robo}^{+/+} ;$Robo $^{+/+}$facial axons exited in $\mathrm{r} 4(\mathbf{A})$, while the cell bodies (B) migrated radially to the dorsolateral pial surface of r6 (superficial focal plane shown). C. Axons in Robo1 $^{-/} ;$Robo $^{-/-}$animals were reduced in number and some were dispersed in the rostral-caudal direction. D. Fewer cell bodies were seen in r6, including some that failed to migrate dorsally, and instead remained near the floor plate. Cell bodies that correctly migrated rostral-caudally in Robo1/2 double mutants successfully migrated to the pial surface of r6. E-H. Axon projection patterns of control and mutant embryos at this late stage. E, F. Robo1 ${ }^{+/+} ;$Robo $^{+/+}$facial nerves projected via axons originating in the 
lateral side of r6. The contralateral projections of the IEE were the only axons seen in or across the floor plate. G, H. E13.5 Robo1 $^{-/} ;$Robo $^{-/-}$facial axons projected long distances incorrectly throughout the hindbrain. Axons could be seen projecting anteriorly $(\mathbf{G})$ and posteriorly $(\mathbf{H})$ within the floor plate $(\mathrm{G}$ and $\mathrm{H}$ are from different locations in the same labeled embryo, and at the same magnification). Although it was difficult to find clear examples of multipolar neuron cell bodies, the retrograde label from the exit point labeled cell bodies in the ipsilateral nucleus, in the floor plate, and in the contralateral nucleus, as well as the long axon projections within the floor plate. Axon projections and cell bodies within the floor plate were observed in 3 of 4 Robo1 $^{-1-} ; R_{o b o 2^{-/-}}$embryos and 0 of 6 in $\mathrm{Robo}^{+/+} ; \mathrm{Robo}^{+/+}$. I, J. Schematics of E13.5 FBMN nerve projections demonstrating the dorsolateral and radial migrations of the cell bodies and axons that followed. In controls, axons followed the migration path of the cell bodies to the pial surface of r6 while bundles continued to fasciculate on their way to the $\mathrm{r} 4$ exit point. Cell bodies were arranged lengthwise across the entire pial surface of r6. In Robo1 $^{-1-} ;$ Robo $^{-/-}$animals, cell bodies sent axons out to the contralateral exit point and some cell bodies were ectopically located in the floor plate. A subpopulation of cell bodies also extended long and multiple neurites. $n=6$ controls, n=4 Robo1 ${ }^{-/-}$Robo2 $2^{-/}$. Scale bar $50 \mu \mathrm{m}$. 